\title{
General Discussion to the Papers of Drs Burnside and Cook, Professor Renard and Dr Forner
}

DR MeInecke (Germany). I have just one short question to Dr Cook. What is the normal proportion of your patients in your Unit with regard to the profession?

DR Cook (G.B.). You are asking me figures which I do not have with me, but I can assure you that all the factors were related statistically. I think I can tell you, in tetraplegia in 70, non-manual I7, skilled manual 27, partially skilled I4, and unskilled I2.

DR H. HACHEN (Chairman). We've come to the end of this I 977 scientific meeting. I think you will all agree with me that we have had a most meaningful and fine session today and during the past 2 days. I wish to thank all the speakers and I wish to thank you in the audience for having stayed with us till the very end of this meeting. I wish you a happy return home and for those among you who will be in Central Europe next July 1978, I would point out the possibility that they might like to attend the Third World Congress of International Rehabilitation and Medical Association which will take place in Basle, Switzerland, between 2 and 8 July and in this post-graduate scientific teaching programme there will be about ten Symposia on very interesting subjects such as Pain, Spasticity, Neurogenic Bladder, and Sexuality in the Physically Disabled and if anyone would like to participate please write to me soon, since we have a preliminary subscription fee which is considerably lower than the one which will be applied later on next spring. Thank you very much. 